\title{
Differential diagnosis of major depression and bipolar disorder
}

\author{
Andrea Schmitt • Peter Falkai
}

Published online: 30 January 2013

(C) Springer-Verlag Berlin Heidelberg 2013

This issue is dedicated to the differential diagnosis of affective disorders with focus on clinical and neuroimaging markers. From a first view, psychosocial dysfunction is mainly associated with schizophrenia. However, Bottlender et al. [1] analyzed the association between psychosocial function and psychopathology in schizophrenia, schizoaffective and affective disorder. For all diagnostic groups, they found higher levels of psychopathology to be associated with higher levels of psychosocial dysfunction in various domains, highlighting the importance of symptom remission in major psychiatric disorders. Major depression and bipolar disorder are known to have a high heritability. Serretti et al. [2] investigated the impact of a family history on clinical and socio-demographic variables. They found a positive family history more common in bipolar patients than in major depression plus an association with anxiety disorders and age of onset in both diseases. However, hypomania is frequent in patients with major depressive episodes, and the DSM-IV concept of hypomanic episodes should be revised [3].

The serotonergic system, including the serotonin transporter [4] and serotonin 1A receptor genes, plays a major role in the pathophysiology of mood disorders. In a metaanalysis, Kishi et al. [5] are reporting two SNPs of the receptor gene to be associated with major depression and overlapping with bipolar disorder. Therefore, the neurobiological classification of subtypes of mood disorders is an unresolved challenge and alterations in GABA synthesis have been proposed to discriminate unipolar from bipolar I

A. Schmitt $(\bowtie) \cdot$ P. Falkai

Department of Psychiatry and Psychotherapy,

Ludwig-Maximilians-University Munich,

Nußbaumstr. 7, 80336 Munich, Germany

e-mail: Andrea.Schmitt@med.uni-muenchen.de depression [6]. Discrimination of unipolar and bipolar depression at early stages of the illness could help improving specific treatment regimes. Based on a functional MRI paradigm with pattern classification, Grotegerd et al. [7] found feature weights in medial prefrontal and orbitofrontal regions specific for unipolar depression, whereas the dorsolateral prefrontal cortex contributes to classification as bipolar. For negative faces condition, the amygdala showed strong feature weights in unipolar depression, while during positive face presentation, higher amygdala feature weights were detected, thus discriminating between the two diseases. However, the results have to be replicated in a larger group of unmedicated patients. With respect to brain volumes, antipsychotic treatment has been shown to be associated with structural alterations [8]. Keeping this in mind, McFarland et al. [9] report symptom misattribution to be related to increased gray matter volumes of the caudate nucleus, thalamus, insula, putamen and cerebellum in first-episode schizophrenia patients, while in chronic patients under antipsychotic treatment, no volume alterations have been found to be associated with insight.

Although affective disorders are frequent in the postpartum period, knowledge about psychosocial factors influencing maternal health is still sparse. Escribà-Agüir et al. [10] investigated effects of psychological violence, social support and alcohol or drug abuse of the intimate partner on psychological well-being at 5 and 12 months post-partum. While intimate partner violence increased the risk of deficits in well-being, having an unstable social network, alcohol and drug abuse of a family member are predictors of post-partum depression, highlighting the impact of environmental factors. Another risk factor for depression is higher age and decreased functional capacity as a common problem among elderly. In a group of 2,072 individuals living in a low-income area of Sao Paulo and 
aged 65 years or older, Almeida da Silva et al. [11] showed depression to be strongly associated with high functional disability. However, with appearance of depressive symptoms in the elderly, differential diagnosis is early dementia as a major cause for functional deficits.

Unraveling plasma biomarkers pose one of the challenges in psychiatric research. Bipolar disorder has been shown to be associated with a proinflammatory status involving altered plasma cytokine levels [12]. The same group now reports altered levels of chemokines in bipolar disorder [13], contributing to the hypothesis of disturbed immune function. Those findings may lead to better understand disease mechanisms and treatment strategies. Electroconvulsive therapy (ECT) is commonly used in treatment-resistant depression and catatonia. In schizophrenia, ECT may lead to recovery from disruptive behavior [14]. In major depression, synergistic effects of ECT and ketamine anesthesia have been reported to improve cognitive side effects [15]. Estimation of the seizure threshold is used in weighing effectiveness against the risk of side effects. In a prospective study, van Waarde et al. [16] found higher age and bifrontotemporal electrode placement to be predictors for higher seizure threshold levels at different time points, which should be taken into account when selecting ECT dosage. With respect to treatment of affective disorders, new treatment strategies based on mechanisms of neuroplastic processes should be developed and lead to regeneration of disturbed brain function.

\section{References}

1. Bottlender R, Strauss A, Möller H-J (2012) Association between psychopathology and problems of psychosocial functioning in the long-term outcome of patients diagnosed with schizophrenic, schizoaffective and affective disorders. Eur Arch Psychiatry Clin Neurosci. doi:10.1007/s00406-012-0335-6

2. Serretti A, Chiesa A, Calati R, Linotte S, Sentissi O, Papageorgiou K, Kasper S, Zohar J, De Ronchi D, Mendlewicz J, Amital D, Montgomery S, Souery D (2012) Influence of family history of major depression, bipolar disorder, and suicide on clinical features in patients with major depression and bipolar disorder. Eur Arch Psychiatry Clin Neurosci. doi:10.1007/s00406-012-0322-y

3. Angst J, Gamma A, Bowden CL et al (2012) Diagnostic criteria for biolarity based on and international sample of 5,635 patients with DSM-IV major depressive episodes. Eur Arch Psychiatry Clin Neurosci 262:3-11
4. Pinto C, Souza RP, Lioult D et al (2011) Parent of origin effect and allelic expression imbalance of the serotonin transporter in bipolar disorder and suicidal behavior. Eur Arch Psychiatry Clin Neurosci 261:533-538

5. Kishi T, Yoshimura R, Fukuo Y, Okochi T, Matsunaga S, Umene-Nakano W, Nakamura J, Serretti A, Correll CU, Kane JM, Iwata N (2012) The serotonin 1A receptor gene confer susceptibility to mood disorders: results from an extended meta-analysis of patients with major depression and bipolar disorder. Eur Arch Psychiatry Clin Neurosci. doi:10.1007/s00406-012-0337-4

6. Gos T, Steiner J, Bielau H et al (2012) Differences between unipolar and bipolar I depression in the quantitative analysis of glutamic acid decarboxylase-immunoreactive neuropil. Arch Psychiatry Clin Neurosci 262:647-655

7. Grotegerd D, Suslow T, Bauer J, Ohrmann P, Arolt V, Stuhrmann A, Heindel W, Kugel H, Dannlowski U (2012) Discriminating unipolar and bipolar depression by means of fMRI and pattern classification: a pilot study. Eur Arch Psychiatry Clin Neurosci. doi:10.1007/s00406-012-0329-4

8. Molina V, Martin C, Ballestros A et al (2011) Optimized voxel brain morphometry: association between brain volumes and the response to atypical antipsychotics. Arch Psychiatry Clin Neurosci 261:407-416

9. McFarland J, Cannon DM, Schmidt H, Ahmed M, Hehir S, Emsell L, Barker G, McCarthy P, Elliott MA, McDonald C (2012) Association of grey matter volume deviation with insight impairment in first-episode affective and non-affective psychosis. Eur Arch Psychiatry Clin Neurosci. doi:10.1007/s00406-0120333-8

10. Escribà-Agüir V, Royo-Marqués M, Artazcoz L, Romito P, RuizPérez I (2012) Longitudinal study of depression and health status in pregnant women: incidence, course and predictive factors. Eur Arch Psychiatry Clin Neurosci. doi:10.1007/s00406-012-0336-5

11. da Silva SA, Scazufca M, Menezes PR (2012) Population impact of depression on functional disability in elderly: results from "São Paulo Ageing \& Health Study" (SPAH). Eur Arch Psychiatry Clin Neurosci. doi:10.1007/s00406-012-0345-4

12. Guimaraes Barbosa I, Barreto Huguet R, Amaral Mendonca V et al (2011) Increased plasma levels of soluble TNF receptor I in patients with bipolar disorder. Arch Psychiatry Clin Neurosci 261:139-143

13. Barbosa IG, Rocha NP, Bauer ME, de Miranda AS, Huguet RB, Reis HJ, Zunszain PA, Horowitz MA, Pariante CM, Teixeira AL (2012) Chemokines in bipolar disorder: trait or state? Eur Arch Psychiatry Clin Neurosci. doi:10.1007/s00406-012-0327-6

14. Kristensen D, Bauer J, Hageman I, Jorgensen MB (2011) Electroconvulsive therapy for treating schizophrenia: a chart review of patients from two catchment areas. Arch Psychiatry Clin Neurosci 261:425-432

15. Kranaster L, Kammerer-Ciernioch J, Hoyer C, Sartorius A (2011) Clinically favourable effects of ketamine as an anesthetic for electroconvulsive therapy: a retrospective study. Arch Psychiatry Clin Neurosci 261:575-582

16. van Waarde JA, van Oudheusden LJB, Verwey B, Giltay EJ, van der Mast RC (2012) Clinical predictors of seizure threshold in electroconvulsive therapy: a prospective study. Eur Arch Psychiatry Clin Neurosci. doi:10.1007/s00406-012-0342-7 